\title{
OPEN Investigating the suitability of poly tetraarylphosphonium based anion exchange membranes for electrochemical applications
}

\author{
Muthumeenal Arunachalam ${ }^{1}$, Alessandro Sinopoli ${ }^{1}$, Farida Aidoudi ${ }^{1}$, Stephen E. Creager ${ }^{2}$, \\ Rhett Smith ${ }^{2}$, Belabbes Merzougui ${ }^{1}$ \& Brahim Aïssa ${ }^{1 凶}$
}

Anion exchange membranes (AEMs) are becoming increasingly common in electrochemical energy conversion and storage systems around the world (EES). Proton-/cation-exchange membranes (which conduct positive charged ions such as $\mathrm{H}^{+}$or $\mathrm{Na}^{+}$) have historically been used in many devices such as fuel cells, electrolysers, and redox flow batteries. High capital costs and the use of noble metal catalysts are two of the current major disadvantages of polymer electrolyte membrane (PEM)-based systems. AEMs may be able to overcome the limitations of conventional PEMs. As a result, polymers with anion exchange properties have recently attracted a lot of attention due to their significant benefits in terms of transitioning from a highly acidic to an alkaline environment, high kinetics for oxygen reduction and fuel oxidation in an alkaline environment, and lower cost due to the use of non-precious metals. The aim of this research was to learn more about the development of a new AEM based on poly tetraarylphosphonium ionomers (PTAP), which has high ionic conductivity, alkaline stability, thermal stability, and good mechanical properties, making it a more cost-effective and stable alternative to conventional and commercial AEMs. A simple solution casting method was used to build novel anion exchange composite membranes with controlled thicknesses using the synthesized pTAP with polysulfone (PS). To ensure their suitability for use as an electrolyte in alkaline electrochemical systems, the composite membranes were characterized using FTIR, XRD, water uptake, ionic conductivity, and alkaline stability. At $40^{\circ} \mathrm{C}$, the PS/pTAP $40 / 60$ percent membrane had a maximum ionic conductivity of $4.2 \mathrm{mS} / \mathrm{cm}$. The thermal and mechanical stability of the composite membranes were also examined, with no substantial weight loss observed up to $150^{\circ} \mathrm{C}$. These findings pave the way for these membranes to be used in a wide variety of electrochemical applications.

The increased awareness of environmental issues and growing demand for sustainable energy sources have led to accelerated research efforts in the field of energy conversion and storage systems ${ }^{1}$. In this regard, Redox Flow Batteries (RFBs) are nowadays gaining momentum due to their suitability for large storage applications ${ }^{2}$. Most electrochemical conversion and storage systems are dependent on ion-exchange membranes. Cation exchange membranes (CEMs) have attracted tremendous attention owing to their high ion conductivity and chemical stability. However, applications of CEMs suffer from several limitations, such as the requirement of noble metalbased catalyst (e.g. Pt) and high crossover of fuels or positively charged redox species. Despite great success, there are still many challenges to be addressed. These challenges can be mitigated with the use of suitable anion exchange membranes (AEMs).

Polymers with anion exchange properties are currently gaining a lot of popularity. In reality, when AEMs are used, precious metal catalysts are no longer needed, and transition metal catalysts can be used instead. This will promote in parallel: (i) the facile oxidation of hydrogen or alcohol at the anode under alkaline conditions ${ }^{3,4}$, (ii) in an alkaline environment, high kinetics for oxygen reduction and fuel oxidation, and (iii) the restriction of positive species crossover from the anode, which is usually very quick in CEMs due to the opposite migration of hydroxide ions from the cathode to the anode $e^{5,6}$.

\footnotetext{
${ }^{1}$ Oatar Environment and Energy Research Institute, P.O. Box: 34110, Doha, Qatar. ${ }^{2}$ Department of Chemistry and Center for Optical Materials Science and Engineering Technology, Clemson University, Clemson, SC, USA. ${ }^{\circledR}$ email: baissa@hbku.edu.qa
} 


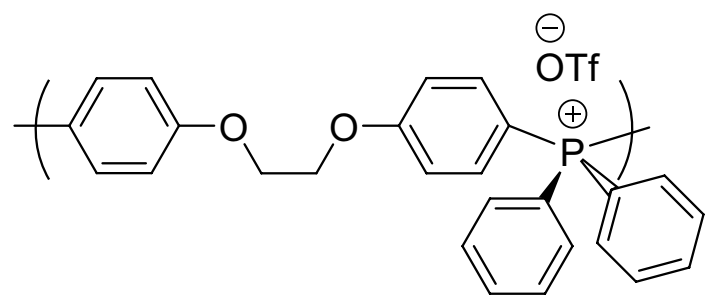

Figure 1. The structure of tetraarylposphonium polymer ${ }^{19}$.

Many research efforts have been centered on the production of AEMs in recent years, which have primarily been based on polystyrene cross-linked with divinylbenzene with the quaternary ammonium group linked to a benzylic methylene group. Because of their low cost and ease of synthesis, these polymers were used in early studies $^{7}$. They do, however, have a range of disadvantages, including low chemical and thermal stability, as well as reduced processability. Many other polymers such as polyarylene sulfone ${ }^{8}$, poly-phenylene oxide (PPO), polyetherimide, polyether ether ketone $(\mathrm{PEEK})^{9}$, polybenzimidazole ${ }^{10}$, copolymers from vinyl monomers, and grafted fluoropolymers, have been developed as promising alternatives to address these issues, and have been successfully employed as PEM in energy conversion and storage systems, under strongly alkaline and oxidative conditions and at high temperature ${ }^{10}$. Under such extreme conditions, however, none of the commercial AEMs displayed sufficient chemical stability.

Our objective was then to develop alkali stable anion exchange separator, resisting to some forms of decomposition under very strong alkaline conditions. Because organo-phosphonium cations are promising yet much less-studied candidate for alkaline ionomers compared to other quaternary nitrogen or sulphur based organocations ${ }^{11-15}$, we focused hence on developing a new generation of AEMs based on tetraaryl-phosphonium ionomers (pTAP). In fact, upon exposure to concentrated alkali, most simple phosphonium salts decompose in a similar manner to ammonium salts by a combination of nucleophilic attack, proton abstraction or direct attack of hydroxide on phosphorus ${ }^{11,16-18}$. However, tetra aromatic groups attached to phosphorus are much less susceptible to base or nucleophilic attack due to the lack of protons on aliphatic carbons, and they can provide electronic and steric stabilization of the phosphonium center. Based on these considerations, we shed light on the synthesis and formulating methods for developing AEMs based on phosphonium class of polymers. We report on their ionic conductivity along with high alkaline stability, thermal stability, and good mechanical properties, which provide a pathway for the significant advancement over the state of the art AEMs based on nitrogen functional groups.

\section{Results}

Wan et al. have explored various methods to synthesize pTAP polymers ${ }^{19}$. The structure of the synthesized pTAP polymer is shown in Fig. 1, the detailed synthesis is reported in the ESI. The chemical structure of the polymer was confirmed by ${ }^{1} \mathrm{H},{ }^{19} \mathrm{~F}$ and ${ }^{31} \mathrm{P}$ NMR analysis (see ESI). The proton NMR confirmed the presence of aromatic protons in the region between 7.2 and $8.1 \mathrm{ppm}$, whereas the alkyl protons lie at $4.4 \mathrm{ppm}$. In the ${ }^{31} \mathrm{P}$ NMR spectrum, the main phosphonium peak was observed at $23.9 \mathrm{ppm}$, minor peaks attributed to the phosphine oxide end groups were observed between 25.3 and $25.7 \mathrm{ppm} .{ }^{19} \mathrm{~F}$ spectrum shows one dominant peak at $-78.82 \mathrm{ppm}$ assigned to the triflate groups of the polymer backbone.

The triflate anion $\left(\mathrm{CF}_{3} \mathrm{SO}_{3}^{-}\right)$, abbreviated as OTf, can be replaced with any desirable anion including $\mathrm{OH}^{-}$. Initially, $20 \mathrm{wt}$. \% of polysulfone polymer pellets were dissolved in N-Methyl-2-pyrrolidone solvent with continuous stirring at $40^{\circ} \mathrm{C}$ until a homogenous solution was obtained. The casting dope was prepared by adding various appropriate weight ratios (40-70 wt.\%) of pTAP ionomer polymer to the already dissolved PS solution and the total polymer solution is $20 \mathrm{wt}$. \%. The resulting solution is stirred continuously for $24 \mathrm{~h}$ until the blend turned into a homogenous solution. The required weight percent of pTAP is restricted to $70 \mathrm{wt} . \%$ due to the aggregation of particles in the polysulfone matrix at higher weight percentages.

Fourier transform infra-red spectroscopy. The FTIR spectra of pure pTAP polymer powder, polysulfone and the fabricated composite blend of PS/pTAP are shown in Fig. 2 along with the expanded spectra. Peaks for polysulfone have been assigned by comparison with previously reported analysis ${ }^{20}$. The main absorption bands in Fig. 2a are: 1492 and $1586 \mathrm{~cm}^{-1}$ (C-C in-ring vibration); 1320 and $1297 \mathrm{~cm}^{-1}(\mathrm{O}=\mathrm{S}=\mathrm{O}$ asymmetric stretching vibration); $1233 \mathrm{~cm}^{-1}$ (C-O stretching vibration); 1163 and $1152 \mathrm{~cm}^{-1}(\mathrm{O}=\mathrm{S}=\mathrm{O}$ symmetric vibration) and $1015 \mathrm{~cm}^{-1}$ (aryl groups). In Fig. 2c, the spectra contain all the group frequencies corresponding to the phenyl group even though it is attached to the phosphorous compound. In addition, there are strong absorption bands near $1000 \mathrm{~cm}^{-1}$, and $1147 \mathrm{~cm}^{-1}, 1441$ which are due to the phenyl group attached directly to phosphorus. The broad absorption band at $3421 \mathrm{~cm}^{-1}$ in Fig. $2 \mathrm{c}$ is due to the free hydroxyl group present in the compound and in Fig. $2 \mathrm{~b}$ it might due to the moisture content in the polymer. Hence it is confirmed that the conversion of triflate ions into $-\mathrm{OH}$ has been taken place after immersion in $\mathrm{KOH}$ solution. The characteristic peaks of the pTAP polymer and polysulfone are present in the blended membranes. 


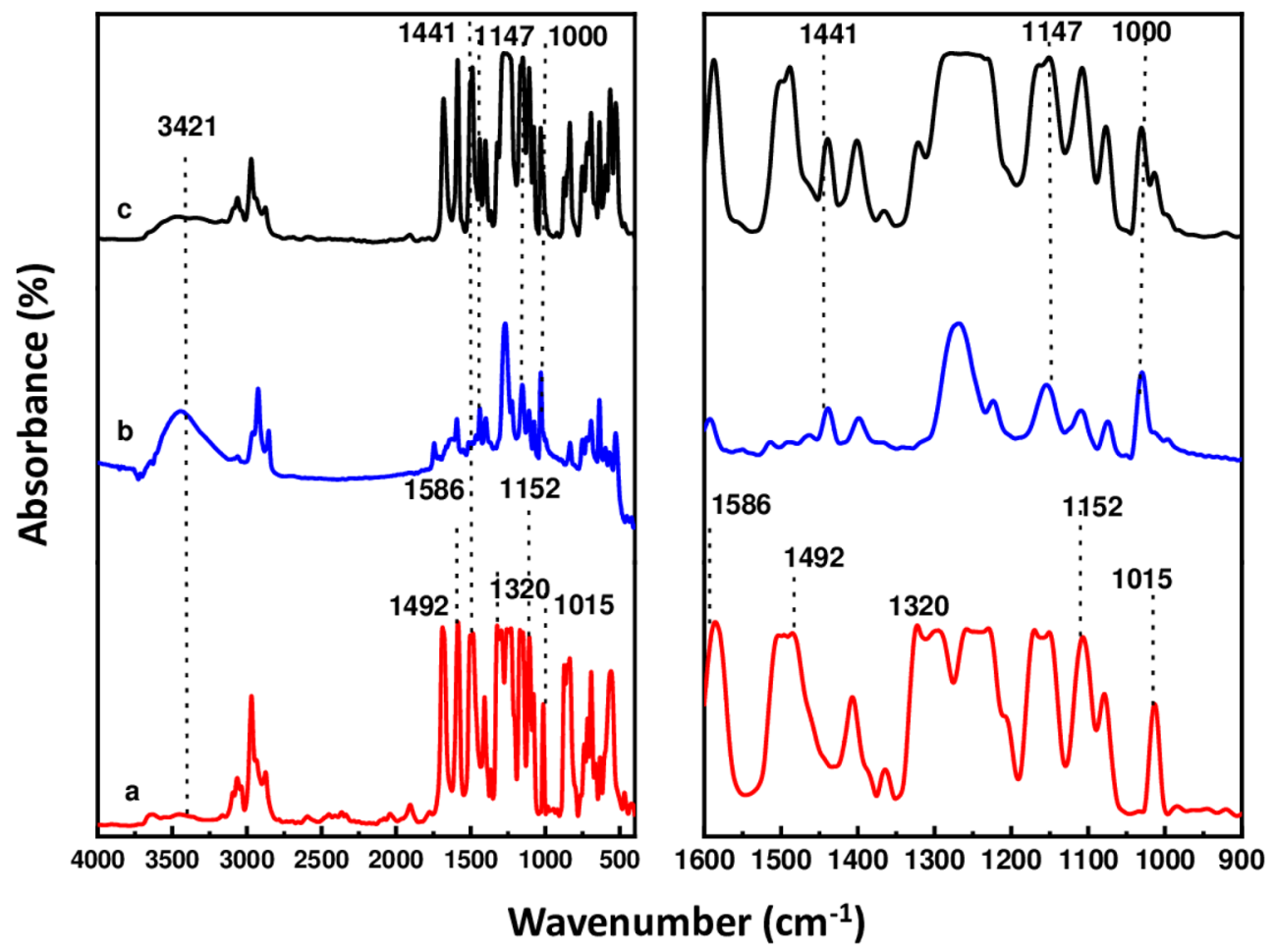

Figure 2. FTIR spectra of membranes (a) polysulfone, (b) tetraarylphosphonium polymer, (c) PS/pTAP (40/60\%) composite membranes.

Ion exchange capacity. It has been widely reported in the literature that the hydroxyl ion conductivity of AEMs is associated with the IEC of the membranes ${ }^{21}$. As a result, increasing the IEC will increase ionic conductivity. Increases in the IEC alone, on the other hand, can result in an excess of water absorption and a large swelling ratio, resulting in dimensional instability. The IEC of the composite blends increased as the weight fraction of pTAP polymer in the composite blend increased in our samples. The IEC values of the fabricated AEMs are in reasonable agreement with literature and they range from $0.95 \mathrm{meq} / \mathrm{g}$ for PS/pTAP $(60 \% / 40 \%)$, to $1.11 \mathrm{meq} / \mathrm{g}$ PS/pTAP (50\%/50\%), up to $1.2 \mathrm{meq} / \mathrm{g}$ for PS/pTAP $(40 \% / 60 \%)$. In order to achieve high IEC, we tried to increase the weight percentage of quaternary phosphonium ion exchange groups beyond $70 \mathrm{wt}$. \% in polysulfone matrix, phase segregation occurred resulting in in-homogeneous membrane. During the membrane forming process with the high amount of PTAP polymer in the polysulfone matrix, we assisted to phase separation and individual precipitation.

Hydroxyl ion conductivity of the composite blend. The ionic conductivity of the composite membranes was analyzed by running electrochemical impedance spectroscopy (EIS) method using potentiostat Biologic SP300. Generally, hydroxyl ion conductivity of AEM is comparatively lower than that of the proton conductivity of PEM due to its difference in size and mobility. In this study, all the composite membranes exhibited favorable conductivities within a range of 0.8 to $4.2 \mathrm{mS} / \mathrm{cm}$, which could meet the requirement for usage. The Nyquist plots of the composite membrane with different weight loadings and with respect to temperature were shown in Fig. 3a,b. The information of bulk resistance can be obtained from the typical AC impedance spectra of composite membranes and it showed the dependence of hydroxyl ion conductivity on ionomer content of the fabricated composite blend membranes. Hence we increased the pTAp ionomer in order to enhance the ionic conductivity from 40 to $60 \%$ in the polysulfone matrix. This can be attributed to the increasing number of ion exchange groups and also the water content, which facilitate the ionic transport ${ }^{22,23}$. The hydroxyl ion conductivity increases from $0.8 \mathrm{mS} / \mathrm{cm}$ to $1.8 \mathrm{mS} / \mathrm{cm}$ with the increasing content of phosphonium ionomer counterpart in the composite blend membrane. The phase segregation morphological structure of Nafion (e.g., proton form) is commonly credited with its outstanding ionic conductivity. The existence of both a strongly hydrophobic fluorocarbon polymer backbone and flexible side chains (that contain ionic groups, sulfonic group) results in the creation of a wider ionic channels between hydrophilic/hydrophobic phase, in which ion-containing hydrophilic domains overlap and form interconnected ionic channels ${ }^{24,25}$. Even though the $\mathrm{OH}^{-}$conduction follows a similar mechanism to $\mathrm{H}^{+}$conduction $^{26}$, the AEMs have lesser ionic conductivity. This might be due to the development of narrow ion-conducting channels between the less hydrophobic polysulfone and also the less hydrophilic pTAP polymer. It is possible to improve considerably the ionic conductivity through the adequate hydrophilicity of polymer electrolytes which in truns leads to higher ion transport properties in the membranes.

Figure 4 depicts the composite membranes' hydroxyl ion conductivity as a function of temperature. The membranes' hydroxide ion conductivity increases as the temperature rises. The maximum hydroxide ion conductivity 
(a)

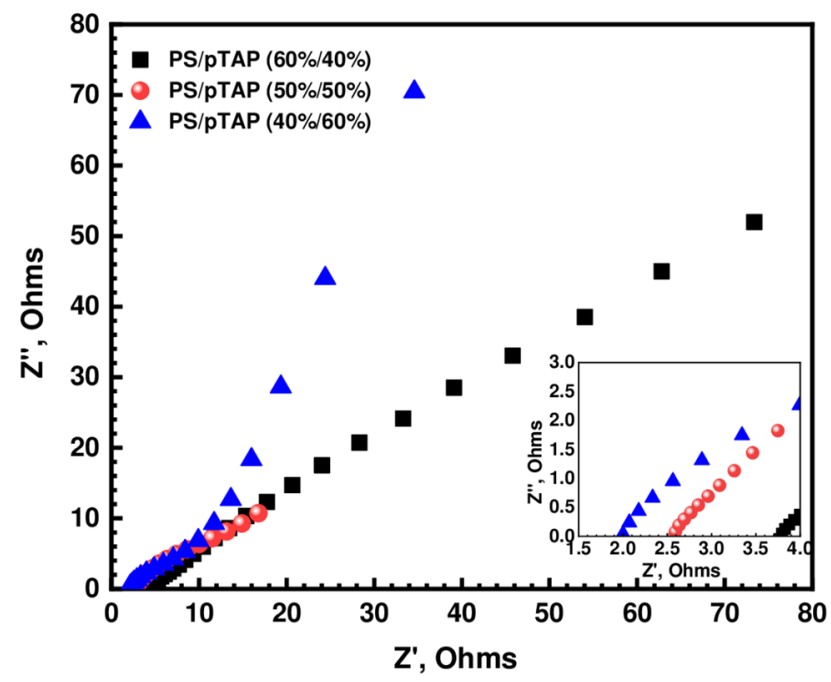

(b)

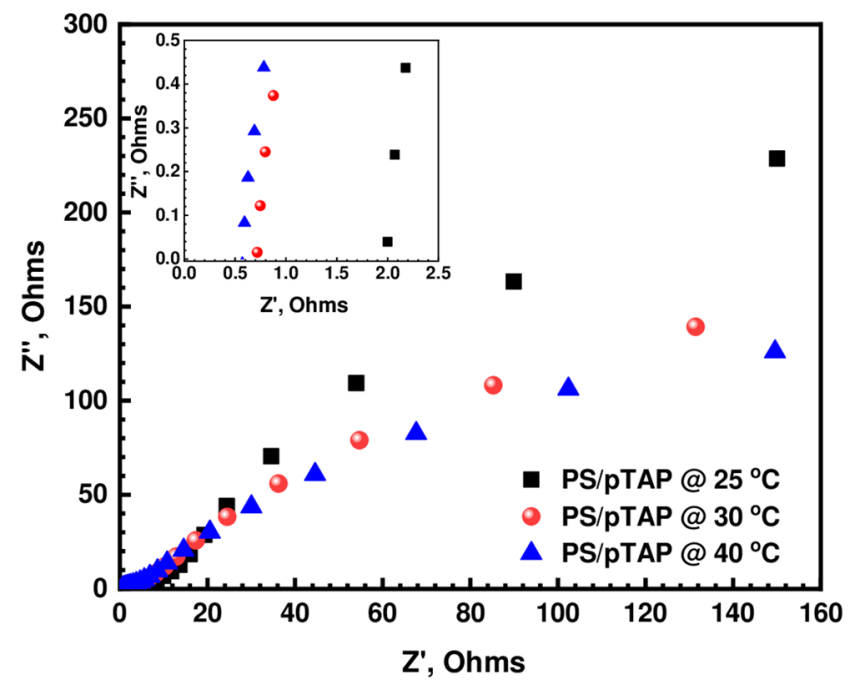

Figure 3. (a) Nyquist plots of PS/pTAP composite membranes with various weight loadings. (b) Nyquist plot for PS/pTAP (40\%/60\%) composite membrane with respect to temperature.

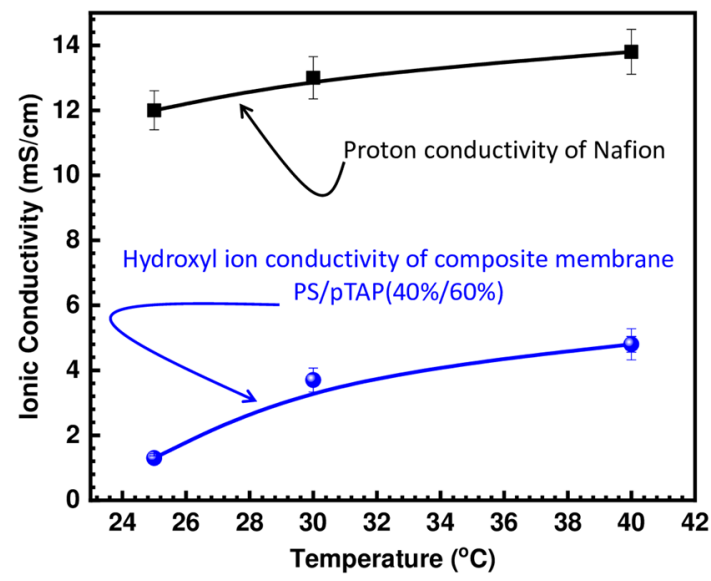

Figure 4. Comparison of ionic conductivity of PS/pTAP (40\%/60\%) composite membrane with Nafion 212.

of the PS/pTAP (40\%/60\%) membrane at $40{ }^{\circ} \mathrm{C}$ was $4.2 \mathrm{mS} / \mathrm{cm}$. This is due to the fact that ions have a higher diffusivity and migrate faster at higher temperatures. Furthermore, at high temperatures, the polymer matrix became more flexible and more water was adsorbed to the membrane, resulting in higher ionic conductivity ${ }^{27}$. The proton conductivity of Nafion is three times higher than that of the hydroxyl ion, as shown in Fig. 4 . The anion conductivity of AEMs may be limited by the poor basicity of the quaternary phosphonium groups combined with the lower mobility of the $\mathrm{OH}^{-}$compared to $\mathrm{H}^{+}$(ion mobility in dilute solution of $\mathrm{H}^{+}=4.76$ and of $\mathrm{OH}^{-}=2.69$ relative to $\mathrm{K}^{+28}$ ). In aqueous solutions, both $\mathrm{H}^{+}$and $\mathrm{OH}^{-}$transport exhibited Grotthuss activity ${ }^{29}$. Hydroxyl anions, on the other hand, have stable solvation shells that reorganize the solvent molecules and disrupt the hydrogen bond network, while hydronium ions are normally incorporated into the hydrogen bond network of water. The ratio between diffusion coefficients of protons $\left(D_{\mathrm{H}}^{+}=9.3 \times 10^{-9} \mathrm{~m}^{2} \mathrm{~s}^{-1}\right)$ and hydroxyl ions $\left(\mathrm{D}_{\mathrm{OH}}{ }^{-}=5.3 \times 10^{-9} \mathrm{~m}^{2} \mathrm{~s}^{-1}\right)$, measured in liquid water at $25^{\circ} \mathrm{C}^{30}$, is about 1.8 , the ratio between the conductivity of Nafion and AEM based on PS/pTAP composites (Fig. 4) is almost double. Eventhough our fabricated membranes have shown a lower ionic conductivity compared to that of the commercial AEMs, including FumasepFAA3 $(40 \mathrm{mS} / \mathrm{cm})$, and AEMION-AF1-HNN5-50-X $(15-25 \mathrm{mS} / \mathrm{cm}))^{31}$, however, our reported values are closely comparable to those reported in the relevant literature. As a matter of fact, the hydroxyl ion conductivities of quaternized/cross-linked PVA-chitosan ${ }^{32}$, PVA-poly (acrylonitrile-co-2-dimethy laminoethyl methacrylate) ${ }^{33}$ and trimethylammonium poly (ether imide) ${ }^{34}$ have been reported in the range of $3-7 \mathrm{mS} / \mathrm{cm}, 3.45 \mathrm{mS} / \mathrm{cm}$, and $2.28-3.51 \mathrm{mS} / \mathrm{cm}$, respectively.

Water uptake. The presence of water in the hydrophilic domains promotes the transport of $\mathrm{OH}^{-}$ions, water uptake is an important parameter in studying AEMs. Higher ionic conductivity is caused by a greater amount of 


\begin{tabular}{|l|l|l|}
\hline Composite blend/PS/pTAP wt.\% & Water uptake at RT/ \% & Water uptake at $60^{\circ} \mathbf{C} / \%$ \\
\hline $60 / 40$ & 5.4 & 7.8 \\
\hline $50 / 50$ & 5.6 & 9.4 \\
\hline $40 / 60$ & 8.6 & 10.3 \\
\hline
\end{tabular}

Table 1. Water uptake for the fabricated PS/pTAP composite membranes.
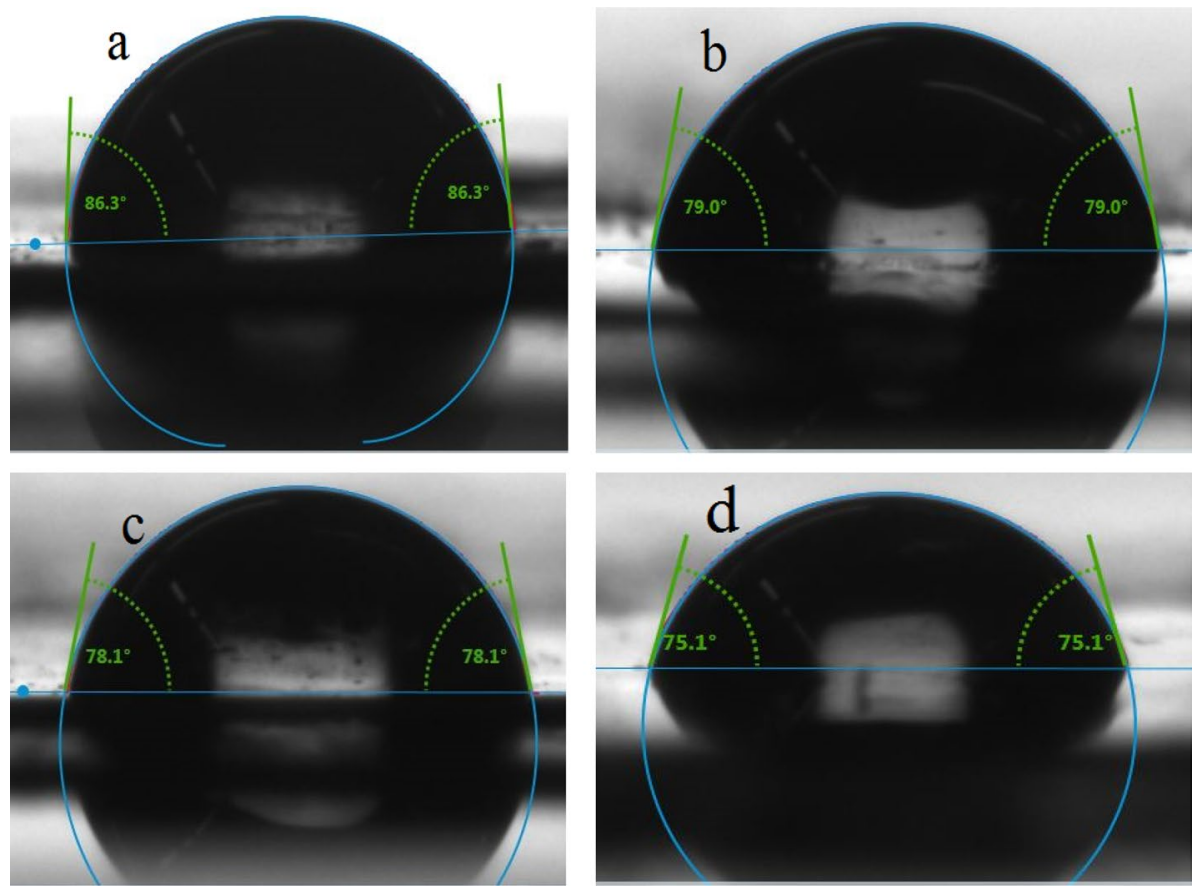

Figure 5. Contact angle of the fabricated PS/pTAP composite membranes, (a) PS/pTAP 100/0, (b) PS/pTAP 60/40, (c) PS/pTAP 50/50, (d) PS/pTAP 40/60.

adsorbed water molecules solvating the polymer moieties to a greater degree. A high water uptake, on the other hand, can result in a loss of mechanical stability.

Since the presence of water is needed for the conduction of ions such as $\mathrm{OH}^{-}$, the structure of hydrophilic domains in a polymer electrolyte is the most important factor in ion conduction. Table 1 shows the water absorption values of composite blend membranes at ambient and $60^{\circ} \mathrm{C}$. Water uptake values increased as the weight fraction of pTAP ionomer in the composite blend membrane increased, as predicted. The increase in incorporated hydrophilic pTAP ionomer materials into the composite blend membranes may be responsible for the increased water absorption ability. The water absorption of the fabricated membranes, on the other hand, increased with temperature, which is due to the increased mobility of polymer chain segments and the increased free volume of the polymer at high temperatures.

Contact angle measurements. The contact angles of the fabricated membranes were measured using the sessile drop method. The hydrophilicity of the PS/pTAP membrane changed after the addition of pTAP. With respect to the amount of pTAP added, the water contact angle observation showed a decreasing trend. The modified membrane with the addition of pTAP had a low water contact angle, with a contact angle of $75.1^{\circ}$ for the $60 \%$ pTAP membrane, suggesting superior hydrophilicity. Figure 5 shows that the contact angles of PS/pTAP membranes decreased, suggesting that the addition of pTAP polymer greatly improved the AEMs hydrophilicity.

Alkaline stability. The acceleration alkaline stability test was conducted by immersing the membrane in $1 \mathrm{M} \mathrm{NaOH}$ at ambient conditions for $300 \mathrm{~h}$, and after that the property of ionic conductivity was measured and we observed that there is no much appreciable change in the ionic conductivity values. The values of ionic conductivity decreased by less than $2 \%$, i.e. from $1.818 \mathrm{mS} / \mathrm{cm}$ to $1.787 \mathrm{mS} / \mathrm{cm}$, and the same trend was also observed with the weight loss measurements which was resulting in less than $2 \%$ loss. Hence, these membranes possessed good alkaline stability and proved to be a viable candidate for working in any alkaline based EES applications. 
(a) Crossover of Vanadium ion through Nafion212

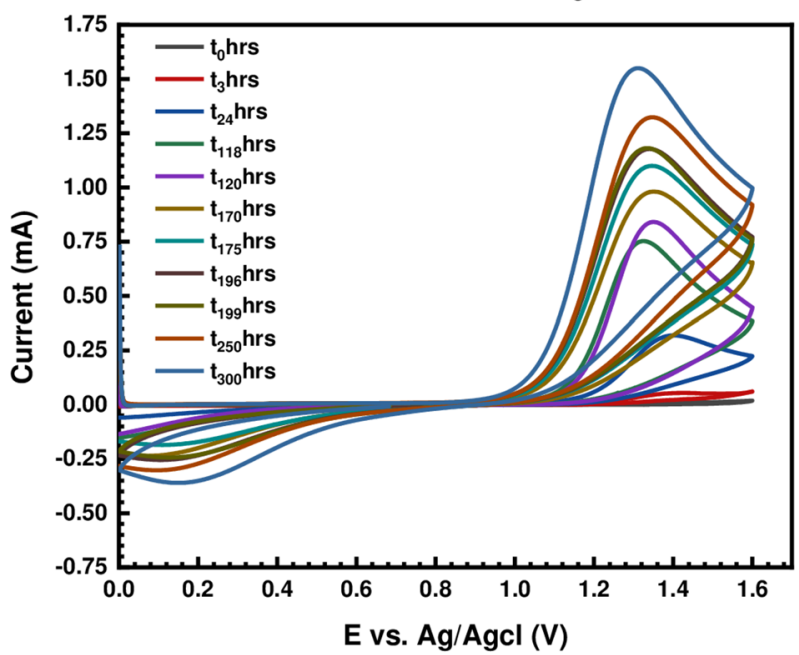

(b) Crossover of Vanadium ion through PS/pTAP membrane

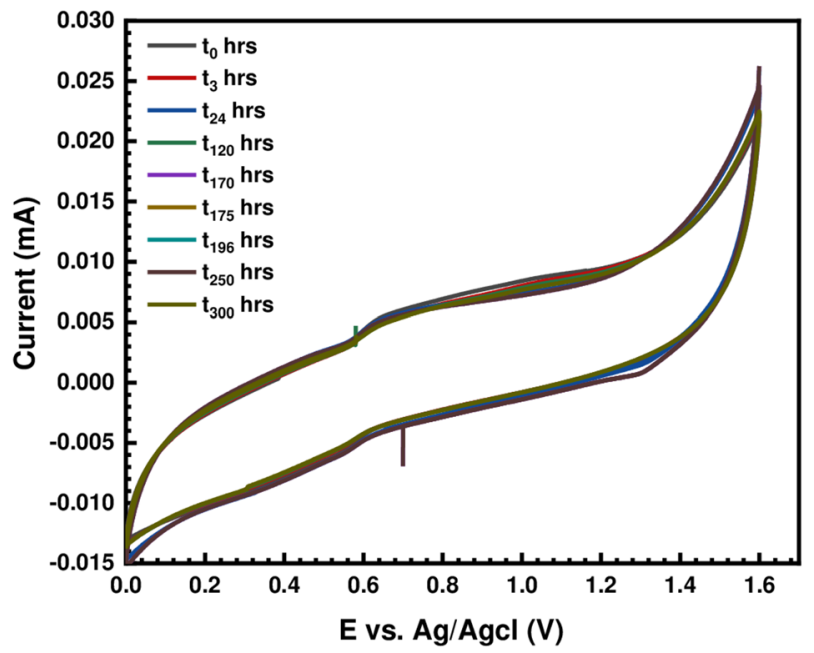

Figure 6. (a) Cyclic voltammogram for the crossover of vanadium through Nafion-212, and (b) PS/pTAP $40 / 60 \%$ composite membrane (right).

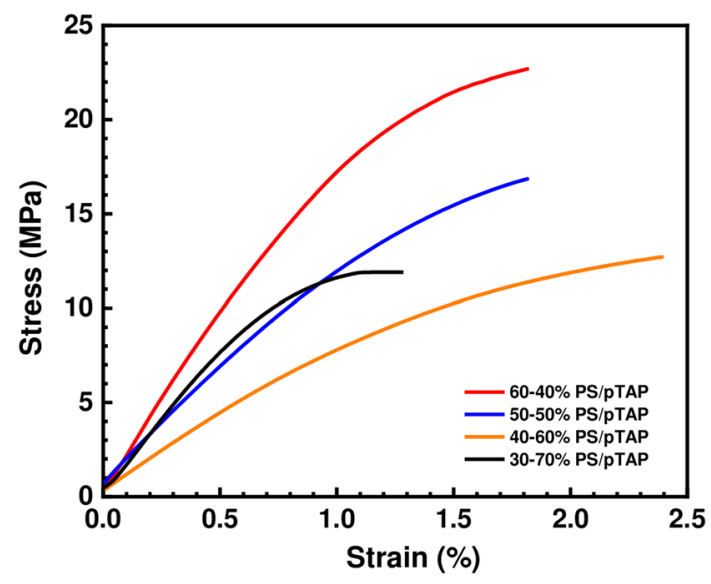

Figure 7. Mechanical stability of PS/pTAP composite blend membranes.

Permeability studies of fabricated composite membranes. The key advantage of AEMs is that they prevent active species cross-mixing by blocking the vanadium cation in RFBs through the Donnan exclusion effect, allowing for the use of more concentrated liquid fuels and thus improving overall system performance. In standard RFB systems, the permeability of vanadium ions plays a direct role in columbic efficiency and selfdischarge rate.

The vanadium permeability of the fabricated PS/pTAP 40\%/60\% membrane and Nafion-212 was investigated in this study using a two compartment cell to evaluate the vanadium ion crossover. Since the thickness of the membranes has a strong impact on the vanadium ion permeability measure, we used a membrane with a thickness equal to Nafion-212 for comparison. Because of the low swelling behavior and repulsion between the vanadium cation and the fixed cationic functional group in the AEM, as defined by the Donnan exclusion effect, the concentration of vanadium through the PS/pTAP membrane was almost negligible compared to that through the Nafion membrane $(1.256 \mathrm{mmol} / \mathrm{h})$. Due to the extremely low water absorption activity, the low IEC value, and the low Donnan effect, no active material permeation was observed at the diffusion cell with the PS/ pTAP ionomer membrane within $300 \mathrm{~h}$ (Fig. 6). The vanadium ion crossover at different time intervals through Nafion-212 and the fabricated pTAP composite blend membrane is shown in Fig. 7.

Mechanical strength. Although having a large number of functional groups on the polymer repeating unit can lead to improved efficiency, it can also lead to a loss of mechanical strength due to increased water absorption and micro voids between the polymer chains. To function optimally, a membrane must have both high mechanical stability and hydroxide conductivity. Tensile test results (see Fig. 7) showed that the tensile strength of the PS/ pTAP membranes was significantly improved compared to that of the pure Nafion membrane. The commercial Nafion 212 membrane exhibited a tensile strength value of $9.0 \mathrm{MPa}^{35}$, which is 3.7 times lower than for the best 
(a)

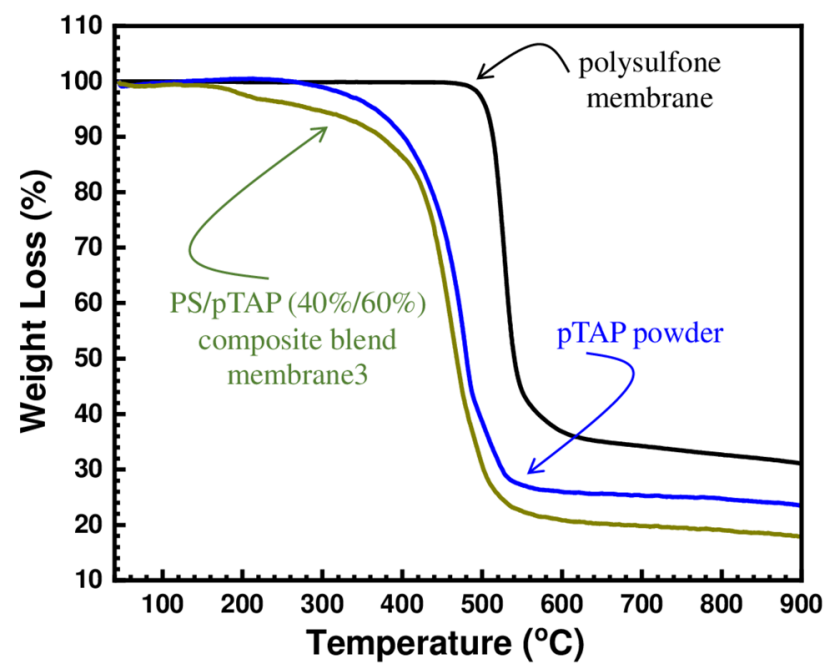

(b)

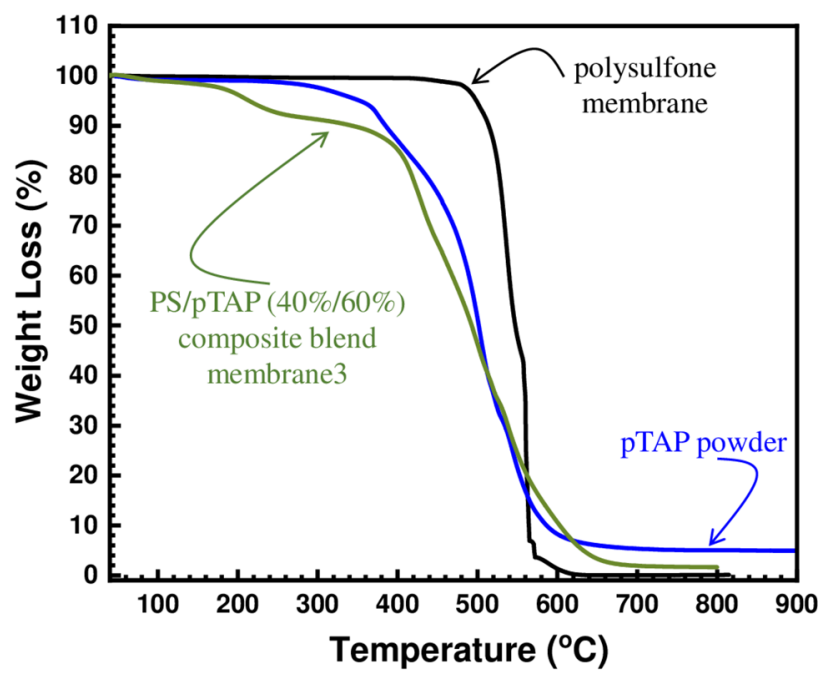

Figure 8. Thermal stability of polymeric based on polysulfone membrane; pTAP powder; and PS/pTAP $(40 \% / 60 \%)$ composite blend membrane in (a) in inert atmosphere and (b) oxygen atmosphere.

composite membrane fabricated in our work. The ultimate tensile strength of the fabricated composite membranes are found to be in the range of 11.8 to $22.5 \mathrm{MPa}$ which is comparable with that of the already reported $\mathrm{AEMs}^{36}$. The PS/pTAP (60\%/40\%) showed the tensile strength and elongation-at-break of $22.5 \mathrm{MPa}$ and $1.8 \%$, while the PS/pTAP (40\%/60\%) showed that of $12.5 \mathrm{~Pa}$ and $2.5 \%$, respectively. This showed that pTAP addition could improve the elongation-at-break and decrease the tensile strength of the PA/pTAP membrane. With the increasing of pTAP content from 40 to $70 \mathrm{wt}$. \%, the tensile strength of the PS/pTAP membrane decreased from 22.5 to $11.8 \mathrm{MPa}$. The elongation-at-break of the PS/pTAP membrane increased from 1.5 to $2.5 \%$ with the pTAP ionomer content increased from 40 to $60 \mathrm{wt}$. \%. However, when the pTAP content exceeded 60 wt. \%, the elongation-at-break as well as tensile strength values of the PS/pTAP membrane decreased with the pTAP concentration. The enhanced elongation-at-break and reduced tensile strength of the PS/pTAP membrane could be attributed to the appropriate amount of pTAP, which accelerated the rate of plasticization of the PS/pTAP membranes. However, the excess pTAP would have an adverse effect on the mechanical properties of PS/pTAP membrane. Therefore, the concentration of pTAP in the PS/pTAP membrane should not exceed 70 wt.\%.

Thermal stability. The fabricated composite blend membrane was tested by thermogravimetric analysis under argon as well as oxygen atmospheres to evaluate its thermal stability (Fig. 8). Polysulfone membrane was stable up to $400{ }^{\circ} \mathrm{C}$ in argon as well as oxygen atmosphere. The synthesized PS/pTAP composite membrane was stable up to $360^{\circ} \mathrm{C}$ in nitrogen atmosphere without any major weight loss and $4-5 \mathrm{wt}$. \% loss is observed in oxygen atmosphere after $200^{\circ} \mathrm{C}$ which arises due to the elimination of solvent and water molecules. The major weight loss observed above $360{ }^{\circ} \mathrm{C}$ and $400{ }^{\circ} \mathrm{C}$ is due to the main chain degradation of the polymers. The thermogram showed that there is no significant weight loss observed for the -OH converted PS/pTAP composite membrane up to $200{ }^{\circ} \mathrm{C}$ and the 3-4 wt.\% loss observed might be due to the elimination of water and solvent molecules. However, after $200{ }^{\circ} \mathrm{C}$ the weight loss corresponds to the degradation of phosphonium groups attached to the aryl chain. From the thermogram, it is inferred that the polysulfone is highly thermally stable up to $500{ }^{\circ} \mathrm{C}$, compared to pTAP polymer which is stable up to $350^{\circ} \mathrm{C}$. Hence, when the pTAP polymer is added to the polysulfone to form composite blend membrane, its thermal stablility was found to be less than that of the pristine polymers.

It is expected that the weight loss observed above $350{ }^{\circ} \mathrm{C}$ results from decomposition of the polymer backbone. In general conclusion, we can ensure that our polymer in form of blend with polysulfone or alone can be stable at temperature below $200{ }^{\circ} \mathrm{C}$ in both argon and oxygen atmosphere. This is very promising data as the intended applications of such membrane in electrochemical energy devices at temperatures ranged from 50 to $150{ }^{\circ} \mathrm{C}$.

Morphology and surface topography analysis. The morphology of the prepared composite membranes PS/pTAP was investigated by scanning electron microscopy and it is shown in Fig. 9. The dispersion of pTAP polymer in the polysulfone matrix plays a significant role in influencing the physical properties of the membrane. The surface view of the composite blend membranes shows a homogenous and closed-packed structure in the morphology without any obvious phase separation or surface defects indicating the excellent phase compatibility of the pTAP polymer with the polysulfone matrix. The polymer-polymer distribution and polymer-polymer matrix reinforcement play vital roles for both compatibility and mechanical properties of the composite blend membranes. SEM analysis confirmed that the composite blend membranes up to $60 \mathrm{wt} . \%$ of pTAP ionomers are suitable for AEM based systems. Figure 10 indicates AFM 3D images of the PS/pTAP (50\%/50\%) and PS/pTAP (40\%/60\%) composite blend membranes. The thickness of the blend membranes was found to be uniform, with no noticeable change, resulting in improved adhesion properties during membrane 

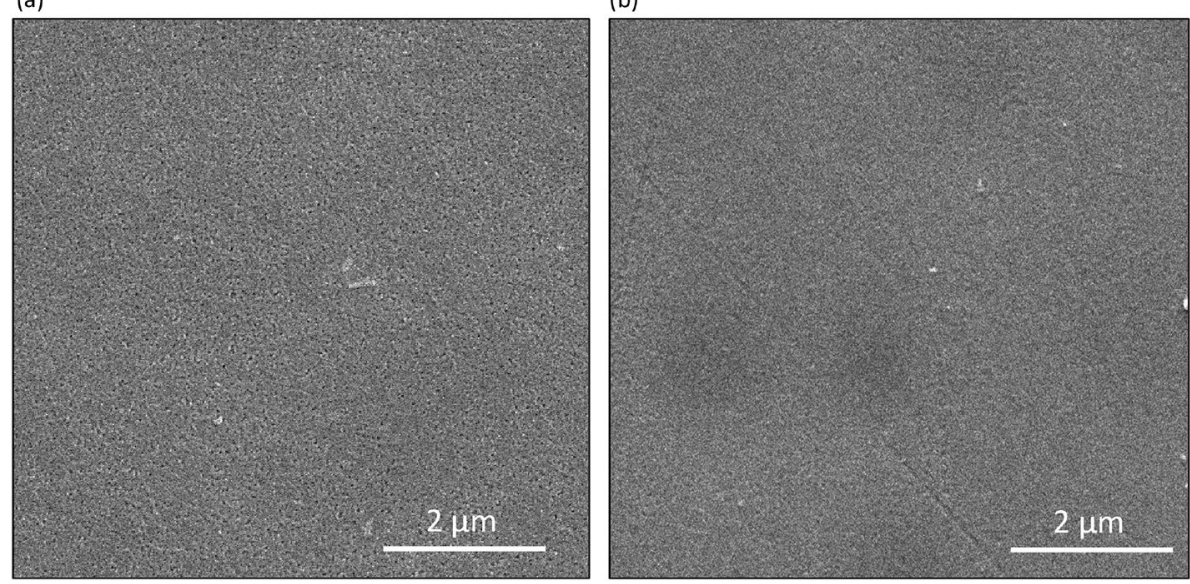

Figure 9. SEM images for (a) PS/pTAP (50\%/50\%) composite membrane, and (b) PS/pTAP (40\%/60\%) composite membrane.

(a)

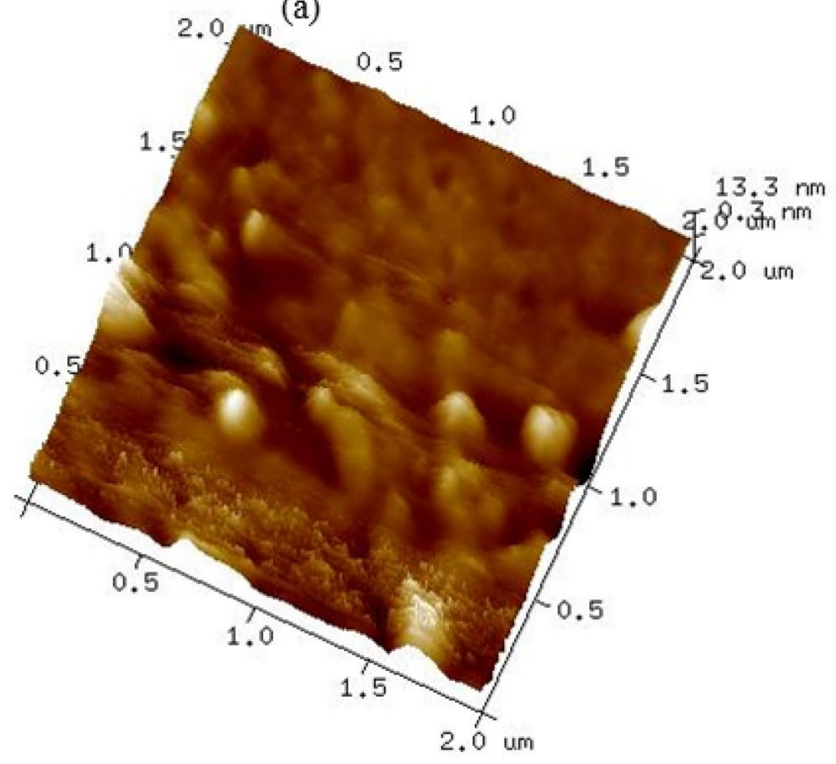

(b)

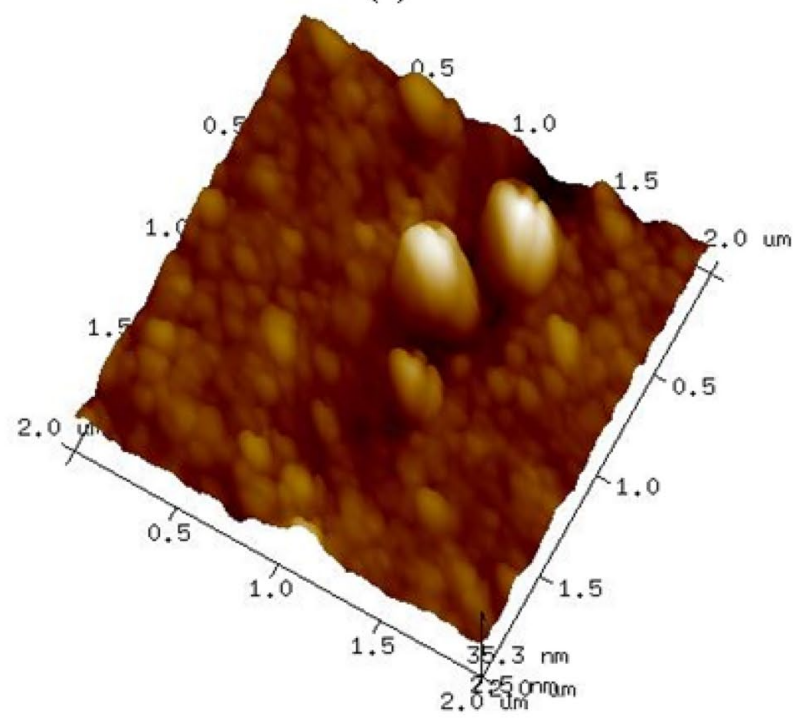

Figure 10. AFM images for (a) PS/pTAP (50\%/50\%) composite blend membrane, and (b) PS/pTAP (40\%/60\%) composite blend membrane.

and electrode assembly fabrication for electrochemical energy conversion/storage systems. The variations in domain hardness are shown by the bright and dark regions in the images. The hydrophobic polymer backbone was assigned to the bright regions, while the dark regions were assigned to a soft structure, which represented the hydrophilic ionomer groups ${ }^{37}$. As the weight percentage of ionomer in the composite blend was increased, the mean roughness of the membranes has increased by 1300\%, i.e. $0.096 \mathrm{~nm}$ to $1.23 \mathrm{~nm}$, indicating the development of a homogenous blend associated with an improvement in the water uptake capacity of blend membranes.

XRD of fabricated composite membranes. Figure 11 shows the XRD spectrum of polysulfone (PSF), which shows a wide, weak diffraction peak located at a $2 \Theta$ value of approximately $17^{\circ}$, suggesting an almost amorphous structure for PSF. The XRD pattern of the composite membrane material with $60 \%$ pTAP had similar characteristic peaks as pure PSF, but there was a slight broadening of the peak, indicating that the incorporation of pTAP polymer within the polysulfone matrix causes a slight increase in polymer chain disorder. As a result, the composite membrane materials have a more amorphous form, which provides a pathway for ionic conduction in the composite membrane.

In summary, the composite membranes based on the PTAP polymer and PS were prepared by solution casting method. Due to the loss in mechanical properties the threshold weight percentage of pTAP content in PS matrix was limited to 60 percent. The thermal and mechanical analysis of the composite membrane revealed good thermal stability up to $200^{\circ} \mathrm{C}$ and adequate mechanical features. From the XRD pattern, it has been observed that 


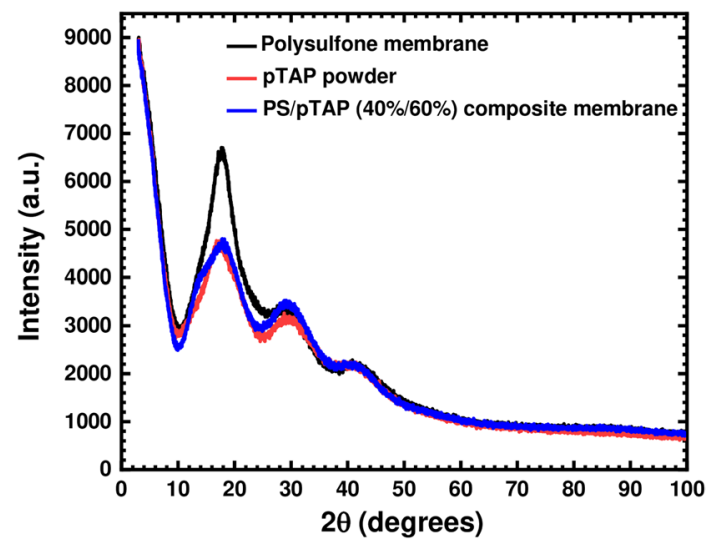

Figure 11. XRD spectra for polysulfone, pTAP polymer and the PS/pTAP composite membrane.

the crystallinity of the PS membrane decreased with the addition of pTAP polymer and makes the composite amorphous in nature. Our investigation shows that the composite membranes possess good ionic conductivity and water absorption properties, which make them suitable to work in alkaline environment. The PS/pTAP $40 / 60 \%$ membrane resulted in a maximum ionic conductivity of $4.2 \mathrm{mS} / \mathrm{cm}$ at $40{ }^{\circ} \mathrm{C}$ and negligible vanadium permeability over $300 \mathrm{~h}$. Altogether, the preliminary analysis here reported on these PS/pTAP composite membranes have demonstrated that they could be potential candidates as polymeric electrolyte membranes in EES applications operating under standard alkaline conditions.

\section{Methods}

All the reagents and solvents were purchased from Sigma-Aldrich, with Analytical grade, and used as received. The tetraarylphosphonium polymer used in our study has been prepared accordingly with literature procedure ${ }^{19}$. NMR spectra were recorded on a Bruker AVANCE III HD $300 \mathrm{MHz}$ NMR spectrometer. NMR data were reported by using Aspin-NMR Data Reporting Tool ${ }^{38}$. The homogenous polymeric solution was cast on a glass tray using a doctor blade, and the thickness of the cast film was adjusted to $60 \mu \mathrm{m}$. The membranes were fabricated by the solvent evaporation technique. After casting, the film was dried in a vacuum oven at $90^{\circ} \mathrm{C}$ for $24 \mathrm{~h}$. After cooling at room temperature, the membrane was peeled off from the glass plate by immersing it in cold DI water. After then it was converted to $-\mathrm{OH}$ form by immersing them into $1 \mathrm{M} \mathrm{KOH}$ solution for $24 \mathrm{~h}$ at ambient conditions. Immersion in $\mathrm{KOH}$ is expected to lead to a hydroxide ion exchange membrane $[\mathrm{pTAP}]\left[\mathrm{OH}^{-}\right]$. This step has been repeated three times to ensure a complete anion exchange. Fourier-transform infrared (FTIR) spectroscopy was performed to confirm the presence of functional groups in the synthesized pTAP polymer and as well as its possible interactions with the polysulfone matrix in the composite blend membranes. The FTIR spectrometer (Alpha Bruker spectrometer) was used for analysis and the spectra were measured over a wave range of $4000-500 \mathrm{~cm}^{-1}$ in absorbance mode by placing the membranes in potassium bromide window. The ion exchange capacity (IEC) was assessed by the titration method. The dried membrane in the hydroxyl form was immersed in $3 \mathrm{M}$ sodium chloride solution for $48 \mathrm{~h}$ at room temperature. The $-\mathrm{OH}^{-}$ions, substituted by $\mathrm{Cl}^{-}$ions, were released into the solution. The solution was then titrated by a $0.01 \mathrm{M} \mathrm{HCl}$ solution using phenolphthalein as an indicator. The IEC of the membranes were calculated using the following equation ${ }^{39}$ :

$$
\mathrm{IEC}=\mathrm{C}_{\mathrm{HCl}} \times \mathrm{V}_{\mathrm{HCl}} / \mathrm{W}_{\text {Dry }}
$$

where $\mathrm{C}_{\mathrm{HCl}}(\mathrm{mol} / \mathrm{l})$ and $\mathrm{V}_{\mathrm{HCl}}(\mathrm{ml})$ are the concentration and volume of $\mathrm{HCl}$ solution required for the neutralization of the residual solution, and $\mathrm{W}_{\text {Dry }}$ is the weight of the dry sulfonated membrane.

The conductivity of the membranes in - $\mathrm{OH}$ form was measured by $\mathrm{AC}$ impedance technique using a Biologic Electrochemical Analyzer. Membrane samples were equilibrated in $1 \mathrm{M} \mathrm{KOH}$ for $48 \mathrm{~h}$ at room temperature before testing. Then the membranes were blot dried with tissue paper and sandwiched between two graphite electrodes of the conductivity cell. The impedance spectra were recorded over the frequency range of $7 \mathrm{MHz}$ with $10 \mathrm{mV}$ oscillating voltage. The membrane conductivity was calculated from the impedance data, using the relation ${ }^{40}$ :

$$
\sigma=\mathrm{L} / \mathrm{RS}
$$

where $\mathrm{L}$ and $\mathrm{S}$ are the thickness and area of the membrane and $\mathrm{R}$ can be derived from the low intersect of the high frequency semicircle on a complex impedance plane with the $\operatorname{Re}(Z)$ axis.

Water uptake measurements were carried out by measuring the change in weight of the membrane before and after hydration. The $-\mathrm{OH}$ form of the membrane was immersed in deionized water at room temperature and equilibrated for about $24 \mathrm{~h}$. The wet weight of the membrane was determined after removing the excess surface water. The percentage of water content was calculated using the following relation ${ }^{41}$ :

Water uptake $(\%)=100 \times[$ Weight of the wet polymer - Weight of the dry polymer $] /$ Weight of the dry polymer 
Water contact angle measurement was measured by sessile drop method, with 250-F1 goniometer (Ramehart Instrument Co, USA) and used to examine the change in hydrophilicity of the fabricated composite blend membranes $^{42}$. The contact angle measurement was then performed as follows. A dangling droplet of $6 \mu \mathrm{L}$ of DI water at the end of 'I'-shaped needle was carefully deposited to membrane surface to avoid the effect of falling force by gravity. Three measurements were taken for each membrane and the average contact angle has been reported. The alkaline stability of the membranes was measured by immersing the sample in $1 \mathrm{M}$ sodium hydroxide solution for $300 \mathrm{~h}^{43}$. The alkaline stability test (or durability test) was performed to analyze the durability of the membrane in the real cell condition. Cyclic voltammetry was used for measuring the vanadium permeability of the membrane. Experiments were carried out at ambient temperature in a two compartment glass cell (with a capacity of $100 \mathrm{ml}$ ) with membrane placed in between, to separate the two half cells. A glassy carbon electrode and smooth platinum electrodes were used as working and counter electrodes, whereas $\mathrm{Ag} / \mathrm{AgCl}$ was used as a reference electrode. The electrolyte used was $2 \mathrm{M}$ vanadium sulfate in $2 \mathrm{M}$ sulfuric acid. The vanadium solution was introduced into the left side of the two compartment cell, and on the right side $2 \mathrm{M}$ sulfuric acid solution was placed. The vanadium permeation from side1 to side 2 through the membrane was observed from the vanadium oxidation currents measured through cyclic voltammetry at various time intervals. The vanadium concentration and diffusion coefficient were determined from the measured transient limiting current density following a potential step. The vanadium flux was established across the membrane due to the concentration difference between the compartments. The vanadium flux was found to be dependent on the state of hydration and on the thermal history of the membrane. The concentration of vanadium in the receiving compartment as a function of time has been calculated as previously reported in the literature ${ }^{44,45}$. The mechanical tensile tests were performed according to the standard method using universal testing machine (Hounsfield Universal Testing Machine). The samples were cut into a size of $5 \mathrm{~mm} \times 50 \mathrm{~mm}$ wide strips and the thickness of each strip was measured with a digital micrometer. The tensile strength of the prepared ion exchange membrane was directly obtained from the tensile tests ${ }^{45-48}$. The thermal stability of the composite blend membrane was examined by the thermogravimetric analyzer (Netzsch Thermal Analyzer). About $10 \mathrm{mg}$ of the sample was used. The experiment was scanned over temperatures between $300^{\circ} \mathrm{C}$ and $800^{\circ} \mathrm{C}$ under nitrogen as well as in the oxygen atmosphere, at a heating rate of $10^{\circ} \mathrm{C} / \mathrm{min}$. The SEM micrographs of the PS/pTAP composite membranes were obtained with the help of Bruker D8 Advance X-ray diffractometer. The AFM 3D topography images of the PS/pTAP composite blend membranes were obtained with Bruker Dimension Icon AFM.

Received: 10 March 2021; Accepted: 24 May 2021

Published online: 05 July 2021

\section{References}

1. Administration, U. S. E. I. Annual Energy Outlook 2021. (2021).

2. Lourenssen, K., Williams, J., Ahmadpour, F., Clemmer, R. \& Tasnim, S. Vanadium redox flow batteries: A comprehensive review. J. Energy Storage 25, 100844. https://doi.org/10.1016/j.est.2019.100844 (2019).

3. Liu, X. et al. Perfluorinated membrane electrode assembly containing metal-free-catalyst cathode for anion exchange membrane fuel cells. J. Electroanal. Chem. 871, 114283. https://doi.org/10.1016/j.jelechem.2020.114283 (2020).

4. You, W., Padgett, E., MacMillan, S. N., Muller, D. A. \& Coates, G. W. Highly conductive and chemically stable alkaline anion exchange membranes via ROMP of trans-cyclooctene derivatives. Proc. Natl. Acad. Sci. 116, 9729. https://doi.org/10.1073/pnas. 1900988116 (2019).

5. Peng, H. et al. Alkaline polymer electrolyte fuel cells stably working at $80^{\circ} \mathrm{C}$. J. Power Sources 390, 165-167. https://doi.org/10. 1016/j.jpowsour.2018.04.047 (2018).

6. Huang, A., Xia, C., Xiao, C. \& Lin, Z. Composite anion exchange membrane for alkaline direct methanol fuel cell: Structural and electrochemical characterization. J. Appl. Polym. Sci. 100, 2248-2251. https://doi.org/10.1002/app.23579 (2006).

7. Wang, L. \& Hickner, M. A. Low-temperature crosslinking of anion exchange membranes. Polym. Chem. 5, 2928-2935. https://doi. org/10.1039/C3PY01490H (2014).

8. Chen, D., Wang, S., Xiao, M. \& Meng, Y. Synthesis and properties of novel sulfonated poly(arylene ether sulfone) ionomers for vanadium redox flow battery. Energy Convers. Manag. 51, 2816-2824. https://doi.org/10.1016/j.enconman.2010.06.019 (2010).

9. Chu, J. Y., Lee, K. H., Kim, A. R. \& Yoo, D. J. Graphene-mediated organic-inorganic composites with improved hydroxide conductivity and outstanding alkaline stability for anion exchange membranes. Compos. B Eng. 164, 324-332. https://doi.org/10.1016/j. compositesb.2018.11.084 (2019).

10. Hu, M., Li, T., Neelakandan, S., Wang, L. \& Chen, Y. Cross-linked polybenzimidazoles containing hyperbranched cross-linkers and quaternary ammoniums as high-temperature proton exchange membranes: Enhanced stability and conductivity. J. Membr. Sci. 593, 117435. https://doi.org/10.1016/j.memsci.2019.117435 (2020).

11. Abraham, S. J. \& Criddle, W. J. Pyrolysis-Gas chromatography of quaternary phosphonium compounds. J. Anal. Appl. Pyrol. 7, 337-349. https://doi.org/10.1016/0165-2370(85)80105-4 (1985).

12. Wada, M. \& Higashizaki, S. A highly basic triphenylphosphine, [2,4,6-(MeO)3C6H2]3P. J. Chem. Soc. Chem. Commun. $482-483$. https://doi.org/10.1039/C39840000482 (1984).

13. Gu, S., Cai, R. \& Yan, Y. Self-crosslinking for dimensionally stable and solvent-resistant quaternary phosphonium based hydroxide exchange membranes. Chem. Commun. 47, 2856-2858. https://doi.org/10.1039/C0CC04335D (2011).

14. Gu, S. et al. Quaternary phosphonium-based polymers as hydroxide exchange membranes. Chemsuschem 3, 555-558. https://doi. org/10.1002/cssc.201000074 (2010).

15. Gu; S. et al. A soluble and highly conductive ionomer for high-performance hydroxide exchange membrane fuel cells. Angew. Chem. 121 (2009).

16. Wang, W. Main Group Element-Containing Chromophores and Polyelectrolytes: Sulfur, Phosphorus and Gallium. PhD thesis, Clemson (2018).

17. Siegel, B. Mechanism of base-promoted phosphonium salt hydrolyses. Kinetics and multiple substituent effects for a nucleophilic attack at phosphorus. J. Am. Chem. Soc. 101, 2265-2268. https://doi.org/10.1021/ja00503a002 (1979).

18. Fenton, G. W. \& Ingold, C. K. CCCVII.-Influence of poles and polar linkings on the course pursued by elimination reactions. Part V. The mechanism of thermal decomposition of quaternary phosphonium hydroxides. J. Chem. Soc. (Resumed). $2342-2357$. https://doi.org/10.1039/JR9290002342 (1929). 
19. Wan, W., Yang, X. \& Smith, R. C. Convenient synthetic route to tetraarylphosphonium polyelectrolytes via palladium-catalyzed P-C coupling of aryl triflates and diphenylphosphine. J. Polym. Sci. Part A Polym. Chem. 55, 1984-1990. https://doi.org/10.1002/ pola.28564 (2017).

20. Dizman, C. et al. Polysulfone/clay nanocomposites by in situ photoinduced crosslinking polymerization. Macromol. Mater. Eng. 296, 1101-1106. https://doi.org/10.1002/mame.201100114 (2011).

21. Gong, X. et al. Design of pendent imidazolium side chain with flexible ether-containing spacer for alkaline anion exchange membrane. J. Membr. Sci. 523, 216-224. https://doi.org/10.1016/j.memsci.2016.09.050 (2017).

22. $\mathrm{Gu}$, S. et al. Synthesis and characteristics of sulfonated poly(phthalazinone ether sulfone ketone) (SPPESK) for direct methanol fuel cell (DMFC). J. Membr. Sci. 281, 121-129. https://doi.org/10.1016/j.memsci.2006.03.021 (2006).

23. Huang, T. et al. Self-crosslinked blend alkaline anion exchange membranes with bi-continuous phase separated morphology to enhance ion conductivity. J. Membr. Sci. 597, 117769. https://doi.org/10.1016/j.memsci.2019.117769 (2020).

24. Li, N. \& Guiver, M. D. Ion transport by nanochannels in ion-containing aromatic copolymers. Macromolecules 47, 2175-2198. https://doi.org/10.1021/ma402254h (2014).

25. Mauritz, K. A. \& Moore, R. B. State of understanding of nafion. Chem. Rev. 104, 4535-4586. https://doi.org/10.1021/cr0207123 (2004).

26. Tuckerman, M. E., Marx, D. \& Parrinello, M. The nature and transport mechanism of hydrated hydroxide ions in aqueous solution. Nature 417, 925-929. https://doi.org/10.1038/nature00797 (2002).

27. Wang, C. et al. Polybenzimidazole/ionic liquid functionalized graphene oxide nanocomposite membrane for alkaline anion exchange membrane fuel cells. Mater. Lett. 173, 219-222. https://doi.org/10.1016/j.matlet.2016.03.057 (2016).

28. Vanysek, P. Handb. Chem. Phys. 83, 76 (2000).

29. Asthagiri, D., Pratt, L. R., Kress, J. D. \& Gomez, M. A. Hydration and mobility of HO- (aq). Proc. Natl. Acad. Sci. U.S.A. 101, 7229. https://doi.org/10.1073/pnas.0401696101 (2004).

30. Wendt, H. Electrochemical Reactor Design. (Von Pickett, D. J. ed.). (Elsevier 1977). 1. Aufl., XX, 434 S., zahlr. Abb., geb., Dfl. 124.00. Chem. Ingenieur Tech. 49, 924-924. https://doi.org/10.1002/cite.330491125 (1977).

31. Henkensmeier, D. et al. Overview: State-of-the art commercial membranes for anion exchange membrane water electrolysis. J. Electrochem. Energy Convers. Storage 18. https://doi.org/10.1115/1.4047963 (2020).

32. Xiong, Y., Liu, Q. L., Zhang, Q. G. \& Zhu, A. M. Synthesis and characterization of cross-linked quaternized poly(vinyl alcohol)/ chitosan composite anion exchange membranes for fuel cells. J. Power Sources 183, 447-453. https://doi.org/10.1016/j.jpowsour. 2008.06.004 (2008).

33. Kumar, M., Singh, S. \& Shahi, V. K. Cross-Linked Poly(vinyl alcohol)-Poly(acrylonitrile-co-2-dimethylamino ethylmethacrylate) Based Anion-Exchange Membranes in Aqueous Media. J. Phys. Chem. B 114, 198-206. https://doi.org/10.1021/jp9082079 (2010).

34. Cao, Y.-C., Wang, X., Mamlouk, M. \& Scott, K. Preparation of alkaline anion exchange polymer membrane from methylated melamine grafted poly(vinylbenzyl chloride) and its fuel cell performance. J. Mater. Chem. 21, 12910-12916. https://doi.org/10. 1039/C1JM12068A (2011).

35. Espiritu, R., Mamlouk, M. \& Scott, K. Study on the effect of the degree of grafting on the performance of polyethylene-based anion exchange membrane for fuel cell application. Int. J. Hydrogen Energy 41, 1120-1133. https://doi.org/10.1016/j.ijhydene.2015.10. 108 (2016).

36. Lin, C. et al. Hydrophobic side chains to enhance hydroxide conductivity and physicochemical stabilities of side-chain-type polymer AEMs. J. Membr. Sci. 585, 90-98. https://doi.org/10.1016/j.memsci.2019.04.066 (2019).

37. del Río, C., Morales, E. \& Escribano, P. G. Nafion/sPOSS hybrid membranes for PEMFC. Single cell performance and electrochemical characterization at different humidity conditions. Int. J. Hydrogen Energy 39, 5326-5337. https://doi.org/10.1016/j.ijhydene. 2013.12.008 (2014).

38. Sinopoli, F. \& Sinopoli, A. ASpin-NMR data reporting tool. Open J. Chem. 2, 9-14 (2019).

39. Kim, D. J., Lee, B.-N. \& Nam, S. Y. Synthesis and characterization of PEEK containing imidazole for anion exchange membrane fuel cell. Int. J. Hydrogen Energy 42, 23759-23767. https://doi.org/10.1016/j.ijhydene.2017.02.199 (2017).

40. Muthumeenal, A. et al. Sulfonated polyethersulfone (SPES) - Charged surface modifying macromolecules (cSMMs) blends as a cation selective membrane for fuel cells. Fuel Cells 14, 853-861. https://doi.org/10.1002/fuce.201400044 (2014).

41. Ran, J. et al. A novel strategy to construct highly conductive and stabilized anionic channels by fluorocarbon grafted polymers. J. Membr. Sci. 549, 631-637. https://doi.org/10.1016/j.memsci.2017.10.050 (2018).

42. Ananth, A., Arthanareeswaran, G. \& Wang, H. The influence of tetraethylorthosilicate and polyethyleneimine on the performance of polyethersulfone membranes. Desalination 287, 61-70. https://doi.org/10.1016/j.desal.2011.11.030 (2012).

43. Lai, A. N. et al. Enhanced performance of anion exchange membranes via crosslinking of ion cluster regions for fuel cells. J. Power Sources 327, 56-66. https://doi.org/10.1016/j.jpowsour.2016.07.043 (2016).

44. Dai, J. et al. A sandwiched bipolar membrane for all vanadium redox flow battery with high coulombic efficiency. Polymer 140, 233-239. https://doi.org/10.1016/j.polymer.2018.02.051 (2018).

45. Yang, Q. et al. Hyperbranched poly(arylene ether ketone) anion exchange membranes for fuel cells. J. Membr. Sci. 560, 77-86. https://doi.org/10.1016/j.memsci.2018.05.015 (2018).

46. Bordjiba, T., Mohamedi, M., Dao, L. H., Aissa, B. \& El Khakani, M. A. Enhanced physical and electrochemical properties of nanostructured carbon nanotubes coated microfibrous carbon paper. Chem. Phys. Lett. 441(1-3), 88-93. https://doi.org/10.1016/j. cplett.2007.04.072 (2007).

47. Whang, S. J. et al. B-doping of vapour-liquid-solid grown Au-catalysed and Al-catalysed Si nanowires: Effects of B2H6 gas during Si nanowire growth and B-doping by a post-synthesis in situ plasma. Nanotechnology 18(27), 275302. https://doi.org/10.1088/ 0957-4484/18/27/275302 (2007).

48. Bentouaf, A. et al. Theoretical investigation of the structural, electronic, magnetic and elastic properties of binary cubic C15-Laves phases TbX2 (X = Co and Fe). J. Alloy. Compd. 689(25), 885-593. https://doi.org/10.1016/j.jallcom.2016.08.046 (2016).

\section{Acknowledgements}

This work was made possible by the support of the National Research Fund (QNRF), through the project \# NPRP-10-0126-170254. Authors express their thanks to Drs. Kamal Mroue, Mujaheed Pasha, Akshath Shetty and Omar Hassan (Core Lab, QEERI) for FTIR, SEM and XRD and TGA measurements. Authors acknowledge the financial support from Qatar National Library (QNL) in generousely covering the publication' fees of this open access journal.

\section{Author contributions}

M.A.: Conceptualization, investigation, measurements, Formal analysis, Data curation, Writing -original draft, Writing-review \& editing. F.A.: Writing—original draft, Formal analysis, Validation, Methodology. S.E.C.: Sample preparation, process optimization, analysis, Writing_original draft. R.S.: Writing_original draft, measurement, Data curation. A.S.: Writing—original draft, Formal analysis, Investigation, Writing-review \& 
editing, Schematic preparation. B.A.: Validation, Formal analysis, Data curation, Resources, Writing -original draft, Writing—review \& editing Project administration. B.M.: Validation, Writing—review \& editing, Project administration, Resources.

\section{Competing interests}

The authors declare no competing interests.

\section{Additional information}

Supplementary Information The online version contains supplementary material available at https://doi.org/ 10.1038/s41598-021-93273-x.

Correspondence and requests for materials should be addressed to B.A.

Reprints and permissions information is available at www.nature.com/reprints.

Publisher's note Springer Nature remains neutral with regard to jurisdictional claims in published maps and institutional affiliations.

Open Access This article is licensed under a Creative Commons Attribution 4.0 International License, which permits use, sharing, adaptation, distribution and reproduction in any medium or format, as long as you give appropriate credit to the original author(s) and the source, provide a link to the Creative Commons licence, and indicate if changes were made. The images or other third party material in this article are included in the article's Creative Commons licence, unless indicated otherwise in a credit line to the material. If material is not included in the article's Creative Commons licence and your intended use is not permitted by statutory regulation or exceeds the permitted use, you will need to obtain permission directly from the copyright holder. To view a copy of this licence, visit http://creativecommons.org/licenses/by/4.0/.

(C) The Author(s) 2021 